Available online on 15.10.2020 at http://jddtonline.info
Open Access to Pharmaceutical and Medical Research
und $2011-18$, publisher and licensee JDDT, This is an Open Access article which permits
unrestricted non-commercial use, provided the original work is properly cited

Open 1 Access

Research Article

\title{
Prescribing Pattern of Drugs Used in Chronic Liver Disease with Co Morbid Conditions and Assessment of Severity using MELD Score: A Prospective Observational Study
}

\author{
Samreen Huma*1, Omer Nishat Fatima ${ }^{1}$, Ishrath Ayesha' ${ }^{1}$, Jamal Mohammed Moiz ${ }^{1}$, Shareef Mohammed \\ Mohiuddin ${ }^{2}$
}

1 Pharm D., Department of Pharmacy Practice, Mesco College of Pharmacy, Hyderabad, Telangana, India

${ }^{2}$ Assistant Professor, Department of Pharmacy Practice, Mesco College of Pharmacy, Hyderabad, Telangana, India

\begin{abstract}
Objectives: To study the prescribing pattern of drugs \& its use in the treatment of CLD \& assess the pattern of co-morbidities associated with CLD. To Study the mortality rate of the patient using MELD score at a department of general medicine at Osmania general Hospi tal to produce a result which would aid better rational drug use and improve quality of life.

Methodology: A Prospective, observational study was carried out at OGH for a period of 6 months in 100 old patients. Population of either sex or $\geq 18$ years of age were included.

Results: In this Study, 91\% Patients were male. The most common affected age group was 31-40 years. Hypertension (HTN) and diabetes mellitus (DM) were the most likely associated comorbidities. Commonly prescribed Drugs were gastrointestinal agents (22.8\%), Antibiotics (19.9\%). The MELD score was found to be between 10-19 with mortality probability of 6\%.

Conclusion: There is a considerable scope for improving prescribing pattern in CLD by minimizing the use, reduction of doses of drugs to reduce the consequence of hepatotoxicity and Antibiotic Resistance. The prognostic impact of individual comorbidities, on the other hand, may point to areas where cirrhosis and comorbid diseases interact. Studies of individual comorbidities may therefore improve our understanding of the pathophysiology of cirrhosis. MELD showed that the subjects were less likely to get a Liver transplant.
\end{abstract}

Keywords: Chronic liver disease (CLD), Model for end stage liver disease (MELD), Diabetes Mellitus (DM), hypertension (HTN)

Article Info: Received 08 Aug 2020; $\quad$ Review Completed 06 Sep 2020; $\quad$ Accepted 16 Sep 2020; Available online 15 Oct 2020

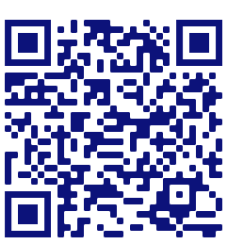

Cite this article as:

Huma S, Fatima ON, Ayesha I, Moiz JM, Mohiuddin SM, Prescribing Pattern of Drugs Used in Chronic Liver Disease with Co Morbid Conditions and Assessment of Severity using MELD Score: A Prospective Observational Study, Journal of Drug Delivery and Therapeutics. 2020; 10(5-s):19-24 http://dx.doi.org/10.22270/jddt.v10i5-s.4336

Huma S, Pharm D., 16-4-340/9/16/2, Kishan bagh, Telangana Hyderabad. 500064, India

\section{INTRODUCTION}

Chronic liver disease occurs when permanent structural changes within the liver develop secondary to long-standing cell damage, with the consequent loss of normal liver architecture. This progresses to cirrhosis, where fibrous scars divide the liver cells into areas of regenerative tissue called nodules. Once chronic liver disease progresses, patients are at risk of developing liver failure, portal hypertension or hepatocellular carcinoma. Cirrhosis is a sequel of chronic liver disease of any etiology and it develops over very variable time periods from 5 to 20 or more years. ${ }^{1}$

\section{Chronic liver disease and co-morbidities}

Co-morbidity is usually defined as a disease coexisting with the disease of interest. Diabetes and cardiovascular (CVS) disorders are common comorbidities associated with liver disease. Patients with liver cirrhosis have interrelated comorbidities with shared risk factors, including hypertension, diabetes, dyslipidemia, hypothyroidism, anemia which can worsen liver functions. Infection and sepsis were also associated co-morbidities in patients with liver disease. Most patients with advanced liver cirrhosis have at least one comorbidity. ${ }^{2}$ Comorbidities must be distinguished from complications such as ascites, variceal bleeding, and hepatic encephalopathy. Complications are at least to some extent a consequence of the portal hypertension and neither loss of 
liver function resulting from cirrhosis, whereas comorbidities are neither causes nor consequences of cirrhosis. ${ }^{3}$

\section{Assessment of disease severity}

The laboratory-based model for end-stage liver disease (MELD) score reflects the Function of the kidney, liver, and extrinsic coagulation pathway and might be used as a general prognostic tool for the assessment of patients. The wellestablished MELD score depends on 3 readily available laboratory variables, serum creatinine, serum bilirubin, and the international normalized ratio (INR). It has been developed and validated to predict mortality in patients with portal hypertension undergoing placement of transjugular intrahepatic portosystemic shunt ${ }^{4}$

\begin{tabular}{|l|l|}
\hline MELD Score Range & Mortality Probability \\
\hline 40 & $71.3 \%$ \\
\hline $30-39$ & $52.6 \%$ \\
\hline $20-29$ & $19.6 \%$ \\
\hline $10-19$ & $6.0 \%$ \\
\hline 9 or less & $1.9 \%$ \\
\hline
\end{tabular}

\section{Drugs to be avoided in impaired hepatic function:}

In cirrhotic patients' serum bactericidal opsonic activity and neutrophil function are defective. This leads to 5 to 7 fold increase in bacteremia in these patients requiring antibiotics for therapeutic or prophylactic purpose Extensive literature search was done to identify the antibiotics that need dosage alteration in patients with liver cirrhosis. ${ }^{5}$

Table 1: Antibiotics to be avoided in Cirrhosis

\begin{tabular}{|l|l|}
\hline Drug & Possible Risk \\
\hline Chloramphenicol & Higher risk of bone marrow suppression \\
\hline Erythromycin estolate & Causes cholestasis \\
\hline Tetracycline & Dose related hepatotoxicity \\
\hline Antituberculous therapy & Pyrazinamide + Griseofulvin is contraindicated \\
\hline Nalidixic acid ,Nitrofurantoin & Prolonged use to be avoided \\
\hline
\end{tabular}

Antituberculosis therapy (ATT) is associated with hepatotoxicity in $10 \%$ of patients. Cirrhotic patients with tuberculosis have significantly lower completion of Rifamipicin + Isoniazid based ATT, higher hepatotoxicity, and higher mortality. Antifungal drugs like Ketocanozole and miconazole though hepatotoxic can be used in patients with cirrhosis but monitor the drug concentration in serum is recommended. Metronidazole reduce dose by $50 \%$ in patients with severe cirrhosis and/or associated renal insufficiency. Antidepressant, (selective serotonin reuptake inhibitors) like fluvoxamine, paroxetine, and fluoxetine need dose modification in patients with cirrhosis. Antiemetic metoclopramide and ondansetron require significant dose reduction in patients with cirrhosis.

As antiulcer agents proton pump inhibitors are preferred over $\mathrm{H} 2$ receptor blockers but they still need half the dosage. Nonsteroid anti-inflammatory agents are contraindicated as they can induce GI bleed and renal failure. Opioid analgesic should be used with caution as it can precipitate encephalopathy. 5

Table 2: Antibiotics to be used with caution in Liver Failure

\begin{tabular}{|l|l|l|}
\hline \multicolumn{2}{|c|}{ Antibiotics Which Need To Be Used With Caution In Patients With Liver Failure } \\
\hline Piperacillin & Ceftriaxone & Fluconozoles \\
& Gatifloxacin & Tetracycline \\
Azithromycin & Cefoperazone & Nalidixic acid \\
Ceftazidime & Erythromycin & Cotrimoxazole+Trimethoprim \\
Pefloxacin & Cefoperazone + & Metronidazole \\
Cefetamet & Sulbactam & \\
Roxithromycin & & \\
\hline
\end{tabular}

\section{MATERIALS AND METHODS}

Study Design: Prospective observational non-invasive study.

Study Site: Osmania General Hospital in Hyderabad, India.

Study Period: 6 months
Sample Size: The sample size of 100 patients was completed.

\section{Inclusion criteria}

All the inpatients admitted in the department of general medicine with chronic liver disease during the study period. Patients of age above 18 years and willing to participate in the study 


\section{Exclusion criteria}

Hospital stays less than $48 \mathrm{hrs}$, Immobilization less than 24hrs, Pregnant and lactatinwomen and Patient with underlying diseases like HIV, AIDS.

\section{Case study procedure}

The study was conducted at the Department of General Medicine. The patients diagnosed with Chronic liver disease will be enrolled in the study based on the study criteria. An Informed Consent was taken from each patient at the time of enrolment in the study. Ethical clearance was accorded by the Institutional Ethical Committee.

\section{Data collection}

All the relevant and necessary data will be collected from patient's case note, Prescription prescribed by the physician, Interviewing patient or patient's care taker.

The prescriptions were chosen based on the inclusion criteria. During the study, the inpatient case records were reviewed which included patient demographics. The information collected was documented in the patient profile form. Data will be analysed and assessed.

\section{Study design}

Patients fulfilling the study criteria were selected. The objectives and the procedure of the study were explained to them and patient consent for participation in the study was obtained. Data on prescribing patterns of CLD with comorbid conditions was collected on appropriate data collection form. Demographic data such as age, sex and Clinical data consisting of history of present illness, past medical history, family history, medication history, social history, co-morbid conditions and associated MELD score was calculated Patients are monitored for the medications given, and other drug interactions.

\section{RESULTS}

\section{Gender Distribution}

In this study, A total of 100 patients was evaluated during a period of 6 months, Out of which (91\%) of the study population were predominantly male and 9 Patients (9\%) were female.

\section{GENDER DISTRIBUTION}

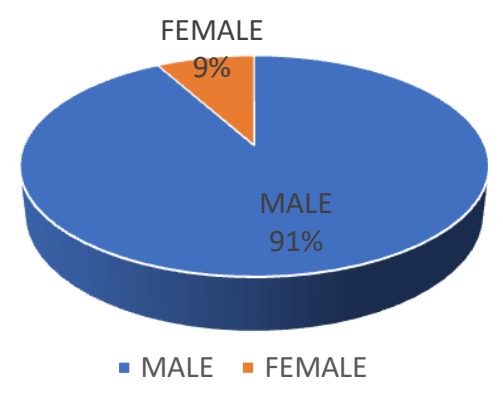

Figure 1: The gender distribution of subjects

\section{Age Distribution}

The age distribution across the study population was found between the age group of (31-40) that is 33\%, followed by the age group of $(41-50)$ that is $31 \%,(61-70) 13 \%,(21-30)$ $13 \%$, and $(61-70) 10 \%$.

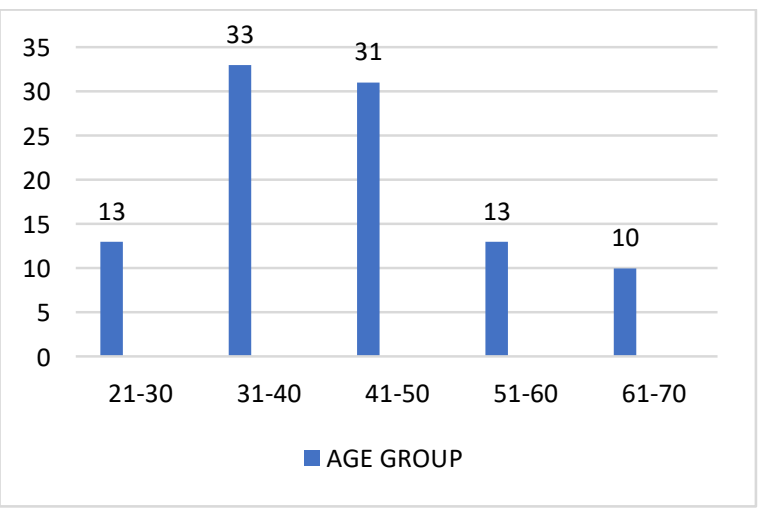

Figure 2: Prevalence of age in study group.

\section{Pattern of Co-morbid conditions and Complications}

Among the study population, we observed that the comorbidities and complications of CLD both were present. The co-morbid conditions were Hypertension 8 (11\%), Diabetes mellitus $8(11 \%)$, UGI bleed. $7(10 \%)$, Cellulitis 5 (7\%), whereas the complications were found to be Coagulopathy 12(17\%), Hepatorenal syndrome 9 (12\%).

Table 3: Incidence of comorbidities and complications

\begin{tabular}{|l|l|l|}
\hline Condition & Number of patients & Percentage (\%) \\
\hline COMPLICATIONS & & \\
\hline Coagulopathy & 12 & $17 \%$ \\
\hline Hepatorenal Syndrome & 9 & $12 \%$ \\
\hline COMORBIDITIES & & \\
\hline Hypertension & 8 & $11 \%$ \\
\hline Diabetes & 8 & $11 \%$ \\
\hline UGI Bleed & 7 & $10 \%$ \\
\hline Cellulitis & 5 & $7 \%$ \\
\hline Anemia & 5 & $7 \%$ \\
\hline Thrombocytopenia & 5 & $7 \%$ \\
\hline Pancytopenia & 5 & $7 \%$ \\
\hline AKI, Hepatitis B \& (Viral) & 3 & $4 \%$ \\
\hline TB & 2 & $2 \%$ \\
\hline CAD & 1 & $1 \%$ \\
\hline
\end{tabular}




\section{Drug Use Pattern}

In the study population various classes of drugs were prescribed, it was observed that the maximum used drugs were Gastointestinal agents (243) followed by antibiotics
(212), dietary supplements(173), hepatoprotectives (119), diuretics (98), hypotensives(62), enzymes(53), (32), Antifibrinolytics(25), Hypotensives(18), Anticoagulants(3) and no NSAID's were prescribed.

Table 4: Drug use among the study population

\begin{tabular}{|c|c|c|c|}
\hline CLASS OF DRUGS & NUMBER OF DRUGS PRESCRIBED & $\begin{array}{l}\text { TOTAL NUMBER OF } \\
\text { DRUGS }\end{array}$ & PERCENTAGE (\%) \\
\hline GASTROINTESTINAL AGENTS & $\begin{array}{l}\text { Pantoprazole (90), Lactulose (74) } \\
\text { Octreotide(29), Ondansetron(28) } \\
\text { Ranitidine(16), Sucralfate (6) }\end{array}$ & 243 & $22.8 \%$ \\
\hline ANTIBIOTICS & $\begin{array}{l}\text { Ceftriaxone (82),Rifaximin (70) } \\
\text { Metronidazole(23), Cefotaxime(18) } \\
\text { Piperacillin+tazobactum(9) } \\
\text { Amoxicillin + Clavunate(6) } \\
\text { Azithromycin(4) }\end{array}$ & 212 & $19.9 \%$ \\
\hline SUPPLEMENTS & $\begin{array}{l}\text { Optineuron(47) } \\
\text { Vitamin k(45), B complex(41) } \\
\text { MVT (13) IFA (12) } \\
\text { Calcium (9),Potassium chloride(3) } \\
\text { Thiamine (3) }\end{array}$ & 173 & $16.2 \%$ \\
\hline Diuretics & $\begin{array}{l}\text { Furosemide(55) } \\
\text { Spironolactone(41) } \\
\text { Mannitol(2) }\end{array}$ & 98 & $9.2 \%$ \\
\hline Anti Hypertensive & $\begin{array}{l}\text { Propranolol(49), Metaprolol(3) } \\
\text { Enalapril (3), Amlodipine (3) } \\
\text { Nefidipine (2),Carvedilol(1) } \\
\text { Hydroxizine HCL (1) }\end{array}$ & 62 & $5.8 \%$ \\
\hline Analgesics & Acetaminophen(26), Tramadol(6) & 32 & $3 \%$ \\
\hline Anti Fibrinolytic & Tranexamic acid (25) & 25 & $2.3 \%$ \\
\hline Hypotensives & Terlipressin (12),Nor-Adrenaline(6) & 18 & $1.6 \%$ \\
\hline Anticoagulants & Enoxaparin(2), Acenocoumarol(1) & 3 & $0.28 \%$ \\
\hline Others & $\begin{array}{l}\text { Insulin(8), Chlorphenaramine(6) } \\
\text { Atorvastatin(3) } \\
\text { Phenytoin(2),Fluconazole(2) } \\
\text { Larinate(2), Digoxin(1) } \\
\text { Prednisolone (1),Sporolac (1) }\end{array}$ & 26 & $2.4 \%$ \\
\hline
\end{tabular}




\section{MELD Score (Model for end stage liver disease)}

Among the Study Population of 100, only 86 patients had the possibility to calculate MELD SCORE. Out of which common range was (10-19) i.e. 41 patients, while 27 patients had scores between (20-29), 11 Patients with Score between (3039), followed by 6 patients (0-9) and 1 patient had scores of 61.

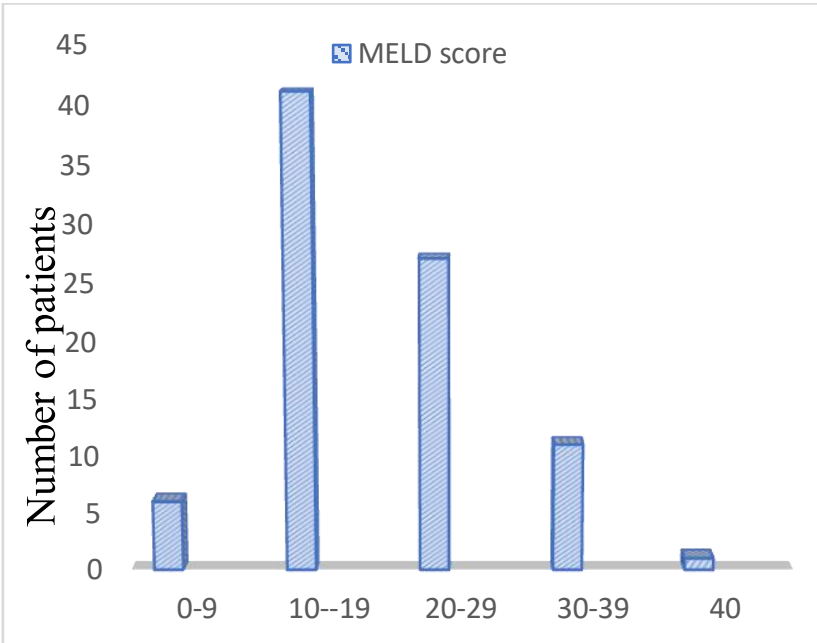

Figure 3: Distribution of population based on MELD score

\section{DISCUSSION}

Among the 100 CLD patients, Males were predominant to females with $91 \%$, they may have greater susceptibility to CLD when compared to female subjects. It was also understood that most of the patients $33 \%$ were in the adulthood (31-40).

The most common Co-Morbid conditions were found to be Hypertension, Diabetes Mellitus, Upper Gastro Intestinal Bleed, Cellulitis with CLD, whereas Dhaya. H, et.al (2016) ${ }^{6}$ carried out a study in which diabetes and hypertension were the frequently observed co-morbid conditions.

Most patients with advanced liver cirrhosis have at least one co-morbidity and worsen complications. Coagulopathy, HRS, ascites were common complications.

Complications are at least to some extent a consequence of the portal hypertension and loss of liver function resulting from cirrhosis, whereas comorbidities are neither causes nor consequences of cirrhosis. Sometimes the distinction is difficult: for example, is hepatocellular carcinoma a complication or comorbidity to cirrhosis? Cirrhosis develops in response to a repeated injury to the hepatocytes, and hepatocellular carcinoma in a cirrhosis patient likely develops in response to the same injury.

A total of 1024 drugs were prescribed and evaluated among these the most commonly prescribed class of drugs were GI agents (243) followed by antibiotics(212), dietary supplements(173), hepatoprotectives (119), diuretics (98), hypertensives(62), enzymes(53), analgesics(32), Antifibrinolytics(25), Hypotensives(18), Anticoagulants(3) which was found to be similar with study carried out by Sathish Kumar.V, et al(2017) ${ }^{7}$.

Proton pump inhibitors and lactulose have been the most frequently used drug among Gastro intestinal agents. Although PPI are considered as safest among the gastro protective the dose of the drugs must be reduced in the patients with liver damage. Antibiotics were the next category that was prescribed to the study population. Among these, Ceftriaxone has been the next most frequently used antibiotic. Parenteral administration of ceftriaxone has been associated with development of biliary sludge and immunoallergic form of cholestatic hepatitis; hence its use must be strictly monitored in CLD patients.

An Increase in the MELD Score is associated with a decrease in Residual Liver Function

Among the study Population of 100 Patients, MELD Score of $47 \%$ of the Patients was between $10-19,31 \%$ of the patients showed with ranges between 20-29, 12\% Patients had MELD Score between 30-29 \& 6.9\% of the Patients had MELD Score between 0-9. Whereas study carried out by Balthasar $\mathbf{L}$. Hug, et.al (2017) ${ }^{8}$ shows Increased MELD scores of 15 to 19 , 20 to 29 , and $\geq 30$ points were positively associated with LOS and the number of comorbidities in uni- and multivariable analysis. Majority of the Prescription were rational

\section{CONCLUSION}

In the present study, we observed the pattern of co-morbid conditions, pattern of drug use and assessment of severity using model for end stage liver disease (MELD)

The co-morbid conditions involved in CLD patients were evaluated and the most Common Co morbid findings were Hypertension \& Diabetes along with Chronic Liver Disease.

Our study suggests that there is a considerable scope for improving prescribing pattern among the health care system by minimizing the use and dose of antibiotics in order to reduce the risk of antibiotic resistance of microbes and immunoallergic reactions. As In this Study Antibiotics were the $2^{\text {nd }}$ Most Used Class of Drugs after Gastrointestinal Agents, making the consequence of hepatotoxicity and antibiotic resistance high, Hence rational use of drugs should be strictly followed.

Based on the MELD, we found that the common Score between 10-19 with Mortality Probability of 6\% which shows the subjects were less likely to get a Liver Transplantation. The pattern of change in liver function tests is characteristic of various diseases and can be instrumental in the identification and differential diagnosis of liver diseases. Prognosis in most of these cases is poor.

In the present study, it was found that liver diseases are correlated with various co-morbidities like DM and HRS disease with most co-morbidities occurring over the age of 40. Multiple organ failure and metabolic disorders lead to increased mortality and morbidity and decreased life expectancy by adding an extra burden to the liver. Hence there is an out most need to monitor the prescribing pattern of the drugs with are used in CLD.

The major complication of liver disease were found to be coagulopathy, hepatorenal syndrome, ascites and encephalopathy More than half the admitted patients have either one or the other of these complications. These complications are markers of disease progression and depict diseases severity in its respective order. Alcohol consumption is related to decrease in mean age of onset of these complications.

\section{ACKNOWLEDMENTS:}

We would like to pass my gratitude for Osmania general hospital for their support during the study and the data collection, Also would like to pass my thanks to our guide and lecturers for their constant support and help. 


\section{REFERENCES:}

1. Roger Walker, Cate Whittlesea. Clinical Pharmacy and Therapeutics", 5th edition, Edinburgh, London New York Oxford Philadelphia St Louis Sydney Toronto 2012. P. 238

2. Namratha A Desai, Kishan P Kotak, Snehal S Patel, "Investigation on epidemiology and etiology of liver diseases and characterization of its association with various factors" International Journal of Pharmacy. Feb 2015; (4):102- 106.

3. Peter Jepsen, "Comorbidity in cirrhosis" World Journal of Gastroenterology, June 2014.

4. Jan A. Roth, Carl Chrobak, Sabine Schädelin, Balthasar L. Hug, "MELD score as a predictor of mortality, length of hospital stay, and disease burden"Wolters Kluwer Health, Inc. 2017

5. Deepak N. Amarapurkar, "Prescribing Medications in Patients with Decompensated Liver Cirrhosis".International Journal of Hepatology, 2011.
6. Arathy.P.C, Vishak Mohan, Al-Muneer.S, Dhanya.A.H, "A Prospective and Observational study on pattern of comorbid conditions in CLD patients with Drug use pattern, and assessment of severity using MELD score". Indian Research Journal of Pharmacy and Science, 2016.

7. Sathish Kumar V, Bhavana P, Supriya.CH, Abdul Rahaman.SK 'Prevalence and Drug Utilization Pattern in Hepatic Impairment Patients at a Tertiary Care Hospital". International Journal of Science and Research (IJSR), 2017.

8. Jan Roth A, Andreas F. Widmer, Sarah Tschudin-Sutter, Marc Dangel, Manuel Battegay, Balthasar Hug.L, "The Model for Endstage Liver Disease (MELD) as a predictor of short-term mortality in Staphylococcus aureus bloodstream infection: A single-centre observational study". Wolters Kluwer Health, Inc 2017. 